\section{Macroscopic Surface Structures formed on Boron upon Solidification}

The purpose of this communication is to report some interesting surface structures that formed on a boron surface upon solidification from the melt. Melting was accomplished by electrical resistance heating of rods of polycrystalline boron about $1 \mathrm{~mm}$. in diameter and several centimetres in length in a helium atmosphere. The current through the rod was slowly increased until it melted at the midpoint at about $2,000^{\circ} \mathrm{C}$. and separated into two pieces, at which time heating ceased and the melted boron, held on the tips of the remaining pieces, solidified and cooled below red heat within a few seconds.

These rods were prepared by the reduction of boron tribromide by hydrogen on a tiny $0.025-\mathrm{mm}$. diameter tungsten filament at about $1,200^{\circ} \mathrm{C}$. The main impurity in the rods was that of the tungsten core, which amounted to about 0.04 mole per cent. Emission spectrographic analysis indicated small amounts of calcium, iron, copper, magnesium and silicon amounting to a total of 0.02 per cent by weight.

Tho photomicrograph in Fig. 1 shows what appears to be a hexagonal spiral pit $0.4 \mathrm{~mm}$. across. Several steps can be seen to extend from the outer edge of the spiral to the centre of the hexagon, where they then taper off and finally disappear. The electrical resistance at room temperature between two tungsten probes placed on the surface of the hexagon was

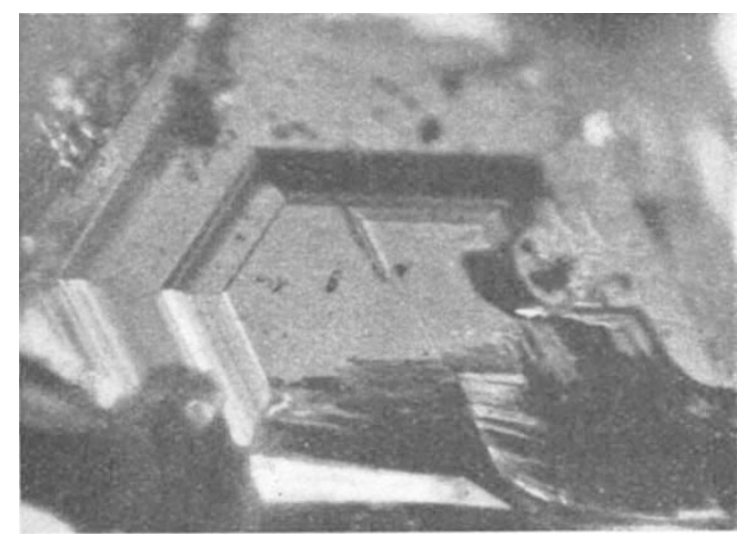

Fig. 1. Hexagonal spiral on boron (0.4 mm. across)

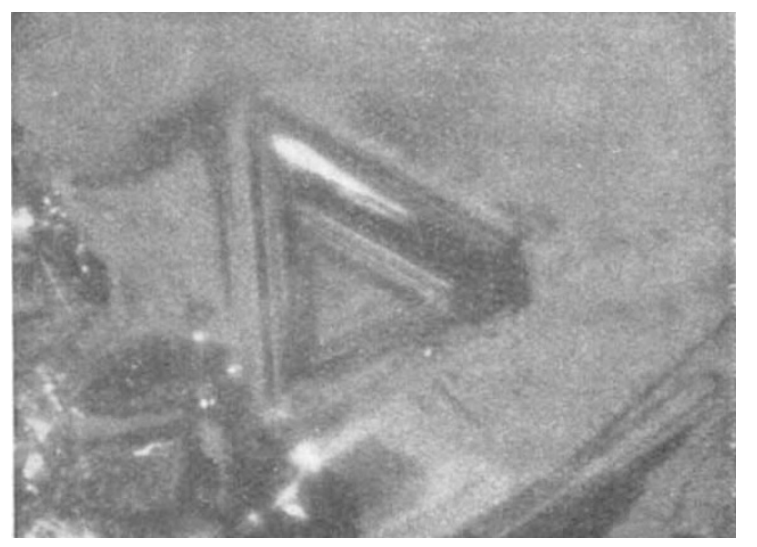

Fig. 2. Pyramidal pit on boron $(0.1 \mathrm{~mm}$, across)

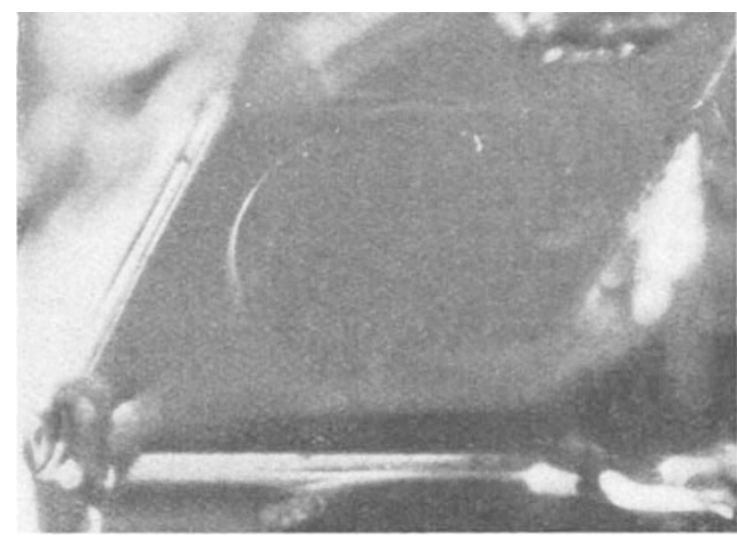

Fig. 3. Oval plateau on boron $(0 \cdot 3 \mathrm{~mm}$. across)

about $50 \times 10^{6}$ ohms. Such a high resistance would be expected for boron but not for tungsten boride. A pyramidal pit approximately $0.1 \mathrm{~mm}$. across at the surface and $0.1 \mathrm{~mm}$. deep is shown in Fig. 2. Another structure observed (Fig. 3) was a highly reflective crystal face in the form of a parallelogram, which contained on its surface an equally smooth oval island several microns in height and about $0.2 \mathrm{~mm}$. by $0.3 \mathrm{~mm}$. across.

This work was supported by the Office of Naval Research, United States Navy.

Claude P. Talley

Experiment Incorporated,

Richmond 2, Virginia.

Sept. 30.

\section{Extractives from Klinki Pine (Araucaria klinkii Lauterbach)}

THE wood of mature klinki pine trees (Araucaria klinkii) frequently contains pink areas running parallel to the grain. When these areas and those closely adjacent to them are moistened with $N$ (or stronger) hydrochloric acid, they become vividly green or green-blue, but after 2-3 days fade to a brown colour. Other acids give either a weaker green colour on fresh semples of the wood or show no reaction. Of the other species of this genus the wood of parana pine ( $A$. angustifolia $O$. Kuntze) frequently shows red-coloured bands, but these do not react in a similar manner when acid is applied to the surface of fresh samples. Dry wood of $A$. bidwillii Hook, $A$. cunninghamii Sweet, $A$. excelsa R. Br., and $A$. montana Bronger et Gris gave no response, but a weak reaction was shown by the woods of $A$. cookii R.Br. and $A$. bernierii Buchh.

When the pink wood of klinki pine was extracted in a Soxhlet with hot methanol, a colourless crystalline material (m.p. 235-38 ${ }^{\circ}, \lambda_{\max } .256 \mathrm{~m} \mu$, yield $0-2 \cdot 5$ per cent) was soon removed, but the components responsible for the green colour reaction were very slowly removed. The yield of the latter varied between 1.3 and 3.4 per cent, with the smallest yield from the most brightly coloured samples, which also contained less crystalline material.

When the non-crystalline fraction, containing six major components (Table 1), was chromatographed on a cellulose column with 6 per cent acetic acid, compounds $B-E$ were obtained in a total yield of 